\title{
Lysophosphatidic Acid Induces \\ Ligamentum Flavum Hypertrophy Through the LPAR1/Akt Pathway
}

\author{
Tangjun Zhou Lin Du Chen Chen Chen Han Xunlin Li An Qin \\ Changqing Zhao Kai Zhang Jie Zhao
}

Shanghai Key Laboratory of Orthopedic Implants, Department of Orthopedics, Ninth People's Hospital, Shanghai Jiaotong University School of Medicine, Shanghai, P. R. China

\section{Key Words}

Ligamentum flavum hypertrophy $\bullet$ Lysophosphatidic acid(LPA) • LPAR1 • PI3K/Akt signaling

\begin{abstract}
Background/Aims: Hypertrophic ligamentum flavum (LF) is a major cause of lumbar spinal stenosis. Our previous work showed that high levels of lysophosphatidic acid (LPA) expression are positively correlated with LF hypertrophy. This study aimed to further unveil how LPA regulates LF hypertrophy. Methods: We studied LPAR1 expression in human LF cells using PCR and western blotting. Cell viability, cell cycle, apoptosis rate and molecular mechanisms were assayed in LPAR1 knockdown or overexpression LF cells. LF hypertrophy and the molecular mechanism was confirmed in human samples and in in vivo studies. Results: The expression of LPA and its receptor LPAR1 is significantly higher in tissues or cells harvested from hypertrophic LF compared to healthy controls. Moreover, LPA promoted LF cell proliferation by interacting with LPAR1. This conclusion is supported by the fact that depletion or overexpression of LPAR1 changed the effect of LPA on LF cell proliferation. LPA also inhibits apoptosis in LF cells through the receptor LPAR1. Importantly, we demonstrated that the LPA-LPAR1 interaction initiated Akt phosphorylation and determined cell proliferation and apoptosis. Our in vitro findings were supported by our in vivo evidence that lyophilized LPA significantly induced LF hypertrophy via the LPAR1-Akt signaling pathway. More importantly, targeted inhibition of LPAR1 by Ki16425 with a gel sponge implant effectively reduced LPA-associated LF hypertrophy. Taken together, these data indicate that LPA binds to the receptor LPAR1 to induce LF cell proliferation and inhibit apoptosis by activating AKT signaling cascades. Targeting this signaling cascade with Ki16425 is a potential therapeutic strategy for preventing LF hypertrophy. Conclusion: LPALPAR1-Akt activation is positively correlated with the proliferation and survival of LF cells. LPAR1 could be a target for new drugs and the development of new therapeutic methods for treating LF hypertrophy.
\end{abstract}

T. Zhou and L. Du contributed equally to this work.

Kai Zhang

and Jie Zhao
Shanghai Key Laboratory of Orthopedic Implants, Department of Orthopedics,

Ninth People's Hospital, Shanghai Jiaotong University School of Medicine (P. R. China)

E-Mail mmc2008@163.com, profzhaojie@126.com 


\section{Introduction}

Lumbar spinal stenosis (LSS) is a spinal degenerative disease that commonly occurs in elderly patients. The symptoms of LSS include low back pain, radiating lower limb pain, and intermittent claudication. Most of the symptoms are caused by compression of the spinal cord, nerve roots, or cauda equine [1]. Ligamentum flavum (LF) is a spinal ligament that covers the posterior and lateral areas of the spinal dural sac. LF hypertrophy is a primary contributor to nerve compression, and it is a cause of LSS symptoms [2].

Like in other fibrotic diseases, fibrosis plays an important role in LF hypertrophy. This was already indicated by the pathological findings in LF hypertrophy [3]. However, the underlying pathophysiological mechanisms remain unknown. Fibrosis in LF appears to be caused by chronic inflammation and injury that leads to fibroblast-mediated wound-healing responses. These wound-healing responses include cell proliferation, migration, collagen synthesis, and extracellular matrix (ECM) remodeling [4].

Lysophosphatidic acid (LPA) is present in most types of mammalian tissues. The highest concentration of LPA is found in the serum $(\sim 10 \mu \mathrm{M})$ and in other body fluids like cerebrospinal fluid [5]. LPA is primarily synthesized by activated platelets [6]. The biological functions of LPA are mediated by six cell membrane receptors. The genes encoding these receptor proteins are designated LPAR1-6 in humans and Lpar1-6 in mice [5]. Among them, LPAR1 is highly expressed in the central nervous system (CNS) and vascular endothelium [7, 8]. LPA activates the LPAR1 downstream signaling cascades via the $G(i) / G(0), G(12) / G(13)$, and $G(q)$ families of heteromeric G proteins. These play a role in cell migration, proliferation, and the response to tissue damage and infectious agents $[5,9]$.

Our group previously used ELISA and immunohistochemistry to show that LPA and LPAR1 are highly expressed in hypertrophied LF [10]. In this study, we examined LPA and LPAR1 expression in hypertrophic LF cells, and we determined their roles on LF cell biology.

\section{Materials and Methods}

\section{LF and cerebrospinal fluid (CSF) specimens}

Hypertrophied LF ( $\geq 5 \mathrm{~mm}$ ) were obtained from 20 patients (10 males and 10 females; average age: $64.8 \pm 1.49$ years old; range: $55-79$ years; thickness of LF: $5.58 \pm 0.219$ ) who underwent decompressive laminectomy for symptomatic degenerative lumber spinal stenosis (LSS) (Fig. 1B, D). Non-hypertrophied LF $(<5 \mathrm{~mm})$ was obtained from 20 patients (10 males and 10 females; average age: $48.67 \pm 2.35$ years old; range: 34-59 years; thickness of LF: 3.06 \pm 0.138 ) with lumbar disc herniation (LDH) who underwent laminectomy to prepare the posterior pathway for discectomy with or without fusion (Fig. 1A, C). The LF were sampled from L4/5 and subjected to histological staining, immunohistochemistry analysis, protein and RNA extraction, and cell isolation (for all online suppl. material, see www.karger.com/doi/10.1159/000487574, Suppl. Table1). CSF was obtained from patients who underwent post-myelographic computed tomography (CTM). These CSFs were subjected to ELISA analysis (R\&D, MN, U.S.A) to determine LPA concentration. This study was approved by the institutional ethics review board, and written informed consent obtained from each patient.

\section{LF cell isolation and culture}

Hypertrophied LF ( $\geq 5 \mathrm{~mm}$ ) was aseptically obtained from four patients with LSS who underwent decompressive laminectomy. Non-hypertrophied LF $(<5 \mathrm{~mm})$ was aseptically obtained from four patients with LDH who underwent laminectomy to prepare the posterior pathway for discectomy (Fig. 1A, C). The LF samples were washed three times with phosphate buffered saline (PBS) and sliced into approximately $0.5 \mathrm{~mm}^{2}$ pieces. After digestion with $0.2 \%$ type I collagenase (Sigma-Aldrich, St Louis, MO, U.S.A) for 90 min, the pieces were washed with Dulbecco's modified Eagle's medium (DMEM; Gibco BRL, Invitrogen Ltd, Carlsbad, CA, U.S.A) 3 times. Next, the LF pieces were placed in T-25 flasks and inverted overnight. Complete DMEM with 10\% fetal bovine serum (Gibco BRL) and antibiotics (100 U/ml penicillin, $100 \mu \mathrm{g} / \mathrm{ml}$ streptomycin) was added, and the samples were incubated in a $5 \% \mathrm{CO}_{2}$ humidified incubator at $37^{\circ} \mathrm{C}$. Cells 


\section{Cellular Physiology Cell Physiol Biochem 2018;45:1472-1486 \\ \begin{tabular}{l|l|l|l} 
DOI: 10.1159/000487574 & $\begin{array}{l}\text { O } 2018 \text { The Author(s). Published by S. Karger AG, Basel } \\
\text { www.karger.com/cpb }\end{array}$
\end{tabular} \\ Zhou et al.: Induction of Ligamentum Flavum Hypertrophy Through LPA-LPAR1-Akt Axis}

were harvested after migrating from the pieces and becoming confluent. The 3rd passaged cells were used for the following experiments. We confirmed that LPAR1 expression showed no obvious changes in the first to third generation of LF cells (see online suppl. material, Suppl. Fig.2B, C).

\section{RNA isolation and real-time PCR}

Total RNA was isolated from LF tissues and cells using a total RNA preparation kit (Axygen, NY, U.S.A) according to the manufacturer's protocol. A first strand complementary DNA (cDNA) synthesis kit (TAKARA, Dalian, China) was used for reverse transcription to prepare first-strand cDNA. Relative mRNA expression was determined using RT-PCR with the GoTaq 1-step RT-qPCR system (TAKARA), agarose gel electrophoresis system (BioRad, CA, U.S.A) and qPCR using SYBR premix Ex Taq kit (TAKARA) with ABI Prism 7500 Fast Real-Time PCR system (Applied Biosystems, CA, U.S.A). Gene expression was quantified using the $2^{\wedge}(-\Delta \Delta \mathrm{Ct})$ method. GAPDH was used as an internal control. The primer sequences were designed using BLAST and summarized in (see online suppl. material) Suppl. Table 2.

\section{Cell viability analysis}

The viability of LF cells after LPA treatment was evaluated with the cell counting kit-8 (CCK-8, Dojindo, Japan). The LF cells with or without LPAR1 knockdown or overexpression or LPAR1 suppression (Ki16425, Selleck, Shanghai, China) were plated in 96-well plates at a density of 5, 000 cells per well and incubated with various LPA (Sigma-Aldrich) concentrations for $24 \mathrm{~h}, 48 \mathrm{~h}, 72 \mathrm{~h}$, and $96 \mathrm{~h}$. The media (complete DMEM with LPA) was changed every 2 days. The cells were washed with PBS before adding CCK-8. Next, $100 \mu \mathrm{L}$ of complete DMEM medium and $10 \mu \mathrm{L}$ of CCK-8 solution were added to each well followed by incubation at $37^{\circ} \mathrm{C}$ for $2 \mathrm{~h}$. The complete DMEM medium and CCK- 8 without cells was used as a blank. The optical density (OD) at $450 \mathrm{~nm}$ was recorded by a microplate reader (BIOTEK, Vermont, U.S.A). Finally, the ODs of the LPA treatment groups were subtracted by their corresponding blank ODs to remove background interference.

\section{LPAR1 knockdown and overexpression}

LF cells were transfected with lentiviral vectors containing small hairpin RNA (shRNA) against LPAR1 (sh1-LPAR1: 5'-GGGAAGAAGTGGATGAGAACG-3'; sh2-LPAR1: 5'-GCACGAGGAGTACCTGAACT-3'), the coding sequences of h-LPAR1 (over-LPAR1: Gene ID: 1902), and a scrambled control (Tongke, Shanghai, China). Vectors were propagated in HEK293 cells, purified, and titered for particle concentration by optical absorbance. The cells were selected in $3 \mu \mathrm{g} / \mathrm{mL}$ of puromycin (Sigma-Aldrich) for $48 \mathrm{~h}$ post-infection and maintained in $1 \mu \mathrm{g} / \mathrm{mL}$ puromycin to remove LF cells that lost their shRNA and overexpression.

\section{Cell cycle analysis}

LF cells with or without LPAR1 knockdown or overexpression were plated in 6-well plates at a density of 200, 000 cells per well. After treating with or without LPA (10 $\mu \mathrm{M})$ for $24 \mathrm{~h}$, the cells were harvested, washed 3 times with PBS, and centrifuged. Cells were fixed with cold $70 \%$ ethanol for at least $24 \mathrm{~h}\left(4^{\circ} \mathrm{C}\right)$. The cell cycle was analyzed by staining with DNA-labeling propidium iodide (Thermo Fisher Scientific, Waltham, MA, U.S.A) and using flow cytometry. The cell cycle diagram obtained by flow cytometry was fitted with Flowjo software (Version 10, FlowJo, LLC). For quantification of this cell cycle diagram, we used the proliferation index $(\mathrm{PI}=(\mathrm{S}+\mathrm{G} 2 / \mathrm{M}) /(\mathrm{G} 0 / \mathrm{G} 1+\mathrm{S}+\mathrm{G} 2 / \mathrm{M}) \times 100 \%)$.

\section{Apoptosis analysis}

LF cells with or without LPAR1 knockdown or overexpression were plated in 6-well plates at a density of 200, 000 cells per well. After treating with or without TNF- $\alpha(10 \mathrm{ng} / \mathrm{mL})$ (Sigma-Aldrich) or LPA (10 $\mu$ M) for $24 \mathrm{~h}$, the cells were harvested, washed 3 times with PBS, and centrifuged. Subsequently, the cells were resuspended in $1 \times$ annexin-binding buffer (Thermo Fisher Scientific). The apoptosis rate was detected using cells staining with annexin V-APC and propidium iodide (both purchased from Thermo Fisher Scientific), and using flow cytometry. To quantify the apoptosis rate, we used the percentage of cell in the upper and lower right quadrant from the flow cytometry diagram.

Western blot analysis

The sliced LF tissues and cells were washed 3 times with PBS and dissolved in RIPA lysis buffer with a protease inhibitor and EDTA (Roche, Grenzach, Germany) to prepare protein homogenates. Equal amounts 


\section{Cellular Physiology Cell Physiol Biochem 2018;45:1472-1486

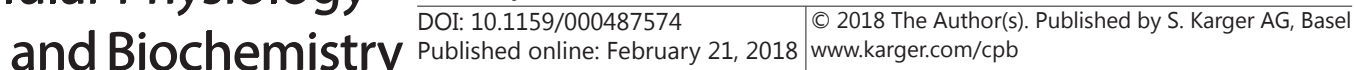 \\ Zhou et al.: Induction of Ligamentum Flavum Hypertrophy Through LPA-LPAR1-Akt Axis}

of protein from LF tissue or cells were separated by $12.5 \%$ or $10 \%$ SDS-PAGE according to the kDA of the targeted protein and transferred to $0.22-\mu \mathrm{m}$ polyvinylidene fluoride (PVDF) membranes (Merck Millipore, CA, U.S.A). The membranes were blocked with 5\% fat free milk at room temperature (RT) for $1 \mathrm{~h}$ and then incubated with primary antibodies (all at 1:1000 dilution) overnight at $4^{\circ} \mathrm{C}$, including rabbit monoclonal antiEDG2 (Abcam, Cambridge, UK), rabbit polyclonal Caspase 3 antibody (Cell Signaling Technology, Danvers, MA, U.S.A), rabbit monoclonal anti-phospho-Akt (Ser308) (CST), rabbit monoclonal anti-phospho-Akt (Ser473) (CST), rabbit monoclonal anti-Akt1 (CST), rabbit monoclonal anti-cdc2 (CST), rabbit monoclonal anti-CyclinB1 (CST) and rabbit monoclonal anti-GAPDH (CST). After 3 washes with Tris-buffered saline containing Tween-20 (TBST), the membranes were incubated with anti-rabbit IgG conjugated with IRDye 800CW (CST) for $1 \mathrm{~h}$ at RT. After 3 washes in TBST, the immunoreactive bands were detected using the Odyssey infrared imaging system (LI-COR). Positive immunoreactive bands were quantified by Image-Pro Plus 6.0 (IPP6.0) software and normalized to GAPDH.

\section{Animals and animal procedures}

Eight-week-old male Sprague-Dawley rate (Shanghai Lab, Animal Research Center Co. Ltd, Shanghai, China) were housed in pathogen-free conditions at $26-28^{\circ} \mathrm{C}$ and $50-65 \%$ humidity. After anesthetizing using an intraperitoneal injection of pentobarbital sodium at a dose of $5.0 \mathrm{mg}$ per $100 \mathrm{~g}$ of body weight, a longitudinal skin incision was made over L1-2 or L2-3 spinous processes of the rats. The paraspinal muscles were detached from the spinous processes. The spinous processes, adjacent supraspinous, and interspinous ligaments were partially removed. The exposed LF and 2 pieces of lyophilized LPA (each containing $10 \mu \mathrm{g}$ of LPA and $1 \mathrm{~g}$ gelatin sponge) or LPA+Ki16425 (10 $\mu \mathrm{g}$ of LPA, $10 \mu \mathrm{g}$ of Ki16425, and $1 \mathrm{~g}$ gelatin sponge) or only the gel sponge as a sham-operation control group were inserted into each side of the posterolateral epidural and LF space. The paraspinal muscles and the skin were sutured. All animal operations were approved by the Animal Ethics Committee of the Shanghai Jiaotong University School of Medicine.

\section{Immunohistochemistry}

LF tissue from patients or rats was fixed with $4 \%$ paraformaldehyde $48 \mathrm{~h}$ after surgery. Sections of LF ( $5 \mu \mathrm{m}$ thick) were obtained to prepare slides. The immunohistochemistry staining procedures for LPAR1 were performed on the slides. The slides were de-paraffinized in graded xylene and rehydrated in graded ethanol solutions. The slides were then incubated in retrieval buffer (Roche) at $37^{\circ} \mathrm{C}$ for $30 \mathrm{~min}$ to retrieve antigen. Endogenous peroxidase activity was blocked in $\mathrm{H}_{2} \mathrm{O}_{2}$ solution $\left(3 \% \mathrm{H}_{2} \mathrm{O}_{2}\right.$ in PBS buffer) at RT for $30 \mathrm{~min}$. The slices were incubated in blocking buffer at RT for $30 \mathrm{~min}$ and subsequently incubated with a primary antibody at $4^{\circ} \mathrm{C}$ overnight. The primary antibody included anti-LPAR1 (CST 1:100), anti-PCNA (CST 1:100), anti-p-Akt (CST 1:100), anti-cleaved Caspase 3 (CST 1:100), and anti-BAX (CST 1:100). Next, the secondary antibody (MaxVision TM HRP-polymer anti-rabbit IHC kit, Maixin-Bio, China) was added for 15 min at RT and DAB (Maixin-Bio) solution was applied as the chromogen. Finally, hematoxylin (SigmaAldrich) was used to counterstain the slices to identify nuclei. A TUNEL assay kit (Roche) was also used to test for apoptosis. DAPI (Sigma-Aldrich) was used according to the manufacturer's protocol to identify nuclei. The images were observed and analyzed using a microscope (Leica DM 4000B) and analyzed with IPP6.0.

\section{Statistical analysis}

All experiments were repeated at least 3 times (see online suppl. material, Suppl. Table 1). Data from all experiments are reported as the mean \pm S.D. The significance of differences within each group was tested with Student's t-test or one-way analysis of variance (ANOVA) by SPSS 19.0 (IBM, Inc.). If the p-value was less than 0.05 , the difference was significant.

\section{Results}

\section{LF cells density was positively correlated with LF thickness}

Non-hypertrophic LF covers the posterior and lateral areas of the spinal dural sac, and it did not compress the dural sac (Fig. 1A). The thickness of LF was less than $5 \mathrm{~mm}$ (Fig. 1C). LF hypertrophy conducted dural sac compression (Fig. 1B) and the thickness of LF was 
Fig. 1. Magnetic resonance imaging (MRI), schematic illustrations of human lumbar spine, lumbar LF general view and HE staining. A, B: T2-weight MRI and schematic illustrations show non-hypertrophic LF of nonlumbar spinal canal stenosis (LSCS) patients. Hypertrophic LF compresses the dural sac and causes LSCS. The red dotted lines indicate the outline of the dural sac. LF, ligamentum flavum; L4, fourth lumbar vertebra; L5, fifth lumbar vertebra. C, D: General views of non-hypertrophic lumbar and hypertrophic LF. E, F: HE staining showed that the density of LF cells was positively correlated with LF thickness. G, H: Cell clusters with disruption of elastic fibers were more common in hypertrophic LF. The blank arrow pointed the direction of the elastic fibers. I: Quantification of cells number per $4 \times$ light microscope. $^{* * *}$ indicates $\mathrm{p}<0.001$.

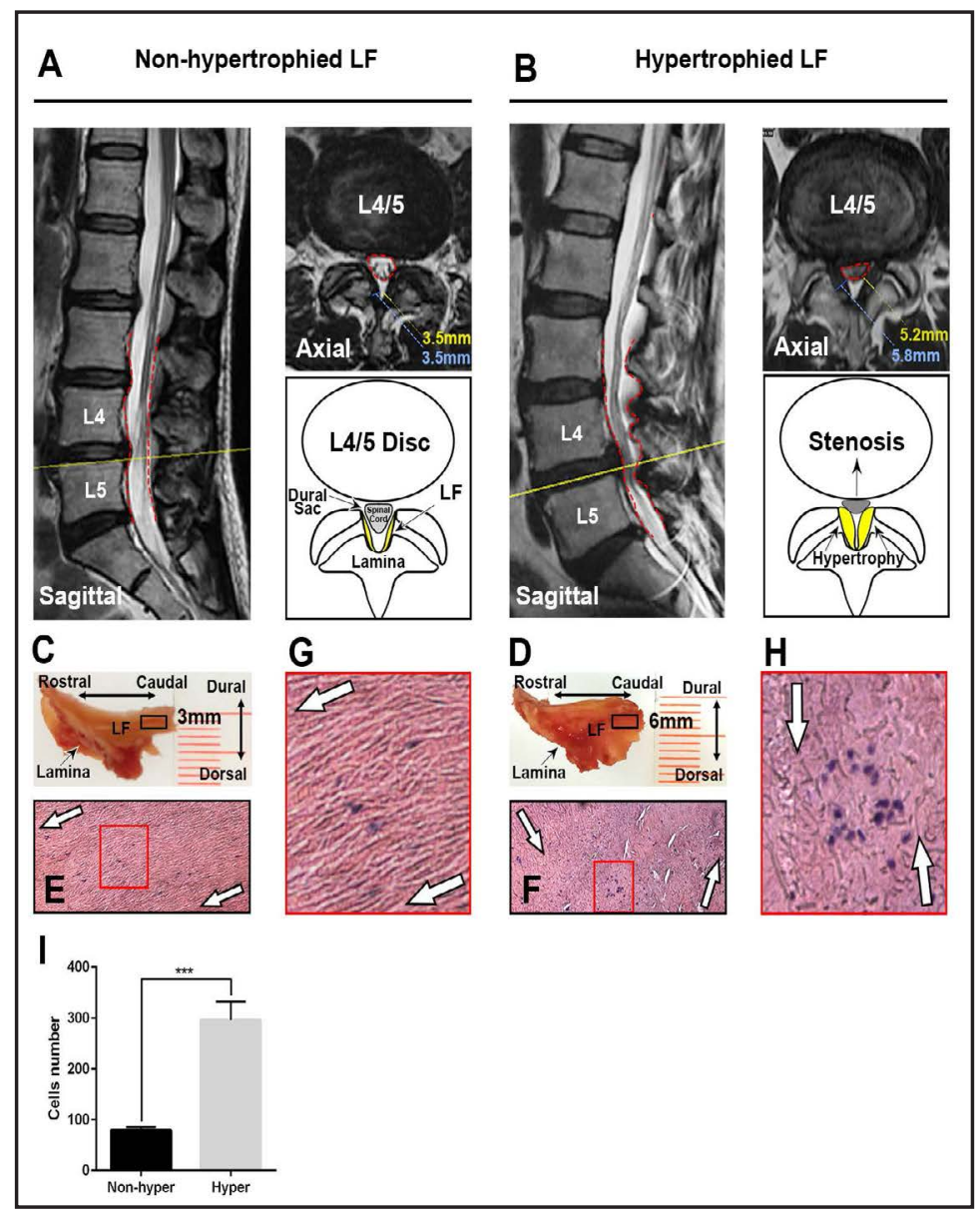

more than 55mm. Using hematoxylin-eosin staining (H\&E), we found that the density of LF cells was significantly higher in hypertrophic LF and that hypertrophic LF tissues became disorganized and showed disruption of elastic fibers (Fig. 1 E, F). We founded that cell clusters were more common and contained many more LF cells in hypertrophic LF compared to nonhypertrophic LF (Fig. $1 \mathrm{G}, \mathrm{H}, \mathrm{I}$ ). These cell clusters indicate that the proliferation of LF cells is much more common in hypertrophic LF.

LPAR1 expression in LF and LPA concentration in CSF are correlated with LF thickness

Based on our RT-PCR, qPCR and western blotting results, LPAR1 expression in hypertrophic LF tissue and cells isolated from hypertrophic LF was significantly higher than non-hypertrophic groups $(\mathrm{P}<0.001)$ (Fig. 2A, B, C). LPAR1 expression was detected using immunohistochemistry on the cell membrane. This showed stronger positive staining in the hypertrophic LF groups than in the non-hypertrophic LF groups (Fig. 2D, see online suppl. material, Suppl. Fig. 2A). In addition, ELISA analysis showed a significant difference in the LPA concentration between the hypertrophic LF group and the non-hypertrophic group (Fig. 2E). The linear regression equation was $Y=1.991 * X+4.593$ ( $X=$ thickness of LF (mm), $\mathrm{Y}=\mathrm{LPA}$ concentration $[\mu \mathrm{M}], \mathrm{R}^{2}=0.842$ ). This indicated that the concentration of LPA in CSF is positively correlated with LF thickness (Fig. 2E).

LPA improves LF cell proliferation by promoting progression through the G2/M cell cycle

After observing that LPAR1 was more highly expressed in hypertrophic LF tissues and cells, we treated LF cells with different concentrations of LPA and continuously observed cell viability using CCK8 for $96 \mathrm{~h}$. The results showed that LF cells showed significantly higher viability in a dose- and time-dependent manner when the concentration of LPA reached a 
Fig. 2. Expression of LPAR1 from LF tissues and cells at the mRNA and protein levels and LPA concentration in CSF. A: RT-PCR and western blot showing that LPAR1 expression is related to $\mathrm{LF}$ thickness. B: Quantification of relative LPAR1 expression in LF tissue between non-hypertrophic LF and hypertrophic LF was compared in RT-PCR and western blotting experiments. C: Quantification of LPAR1 expression between non-hypertrophic LF and hypertrophic LF from LF tissue and LF cells was compared

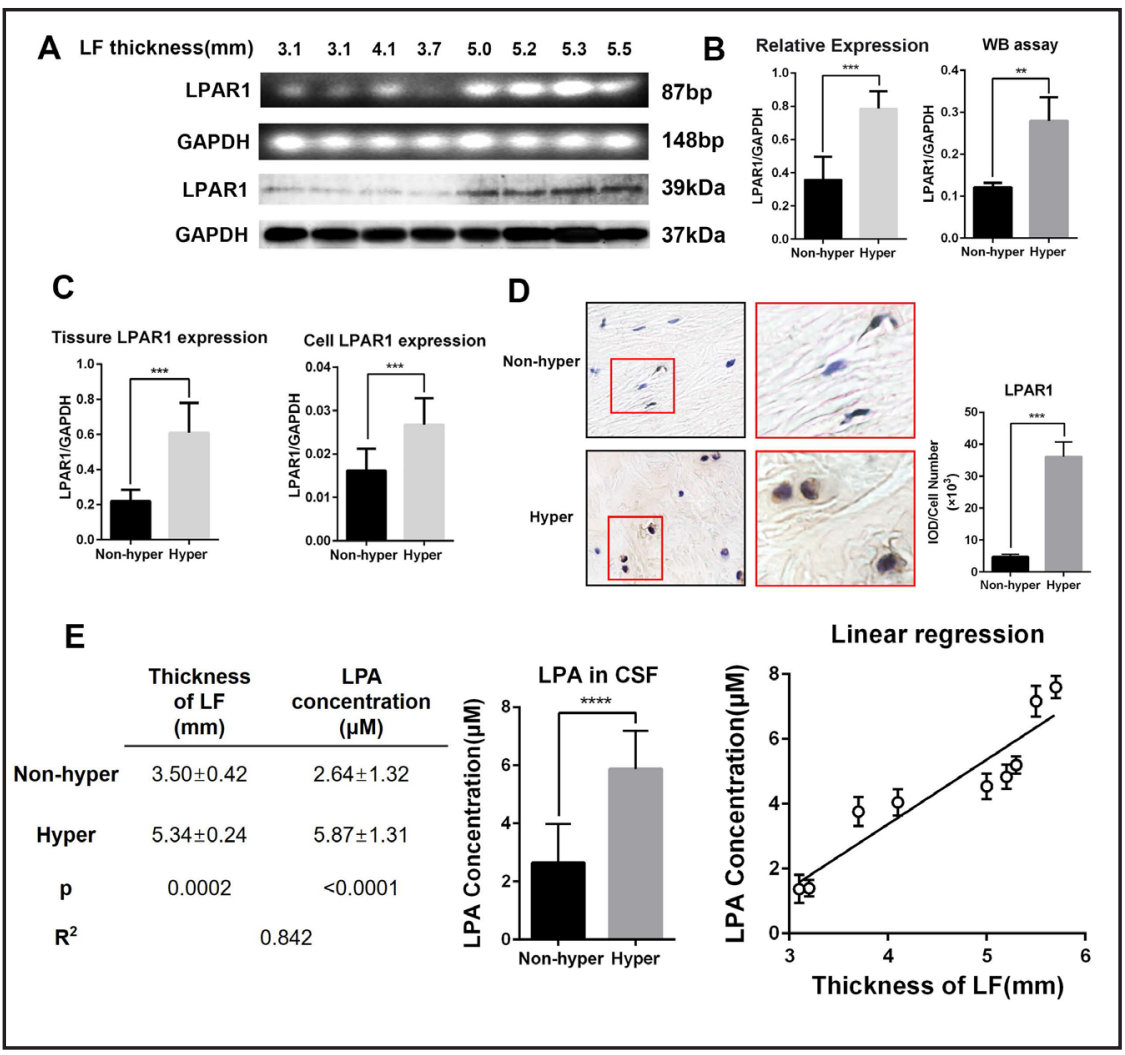
in qPCR experiments. D: LPAR1 expression in LF tissue sections was evaluated via immunohistochemistry; quantification of the positive staining was performed by Image-Pro Plus 6.0. E: The concentration of LPA in CSF was compared between non-hypertrophic LF and hypertrophic LF via ELISA. Linear regression was performed between LF thickness and LPA concentration in CSF. Data are presented as the mean \pm S.D. ** indicates $\mathrm{p}<0.01,{ }^{* * *}$ indicates $\mathrm{p}<0.001,{ }^{* * * *}$ indicates $\mathrm{p}<0.0001$. Non-hyper indicates non-hypertrophic LF. Hyper indicates hypertrophic LF. N indicates number of CSF samples. GAPDH was used as a loading control in western blotting and PCR experiments.

minimal concentration of $0.1 \mu \mathrm{M}$ (Fig. 3A). We used $0,0.1,1$, and $10 \mu \mathrm{M}$ of LPA as the working concentrations and $24 \mathrm{~h}$ as the treatment duration for the following studies. The working concentration of LPA is close to the concentration that we detected in CSF $(2.64-5.87 \mu \mathrm{M})$ and what was previously reported in LF tissues (2.42-2.71 $\mu \mathrm{M})$ [10] and serum $(10 \mu \mathrm{M})$ [5].

To explore the reason for the increased viability of LF cells after LPA treatment, we used qPCR to investigate the underlying mechanisms. We found that CDK1 (cdc2), CDK2, CDK4, CDK6, CCNA2 (CyclinA2), and CCNB1 (CyclinB1) showed a significant increase at the mRNA level, and they acted in a dose-dependent manner (Fig. 3B).

Furthermore, we analyzed the cell viability and cell cycle of LF cells with or without LPAR1 knockdown or overexpression (Fig. 4A, B) using the CCK-8 assay and flow cytometry. The LF cells treated with LPA showed significantly higher cell viability compared to the untreated groups (Fig. 4C). The cell viability of the LPAR1 knockdown LF cells was lower than the control and scramble groups, and LF cells overexpressing LPAR1 showed much greater cell viability than the control and scramble groups (Fig. 4C). Flow cytometry indicated that LPA improved the G2/M phase transition of LF cells (Fig. 4D), and the percentage of G2M phase and the proliferation index of LF cells depleted of LPAR1 was lower than in the control and scramble groups. Moreover, LF cells overexpressing LPAR1 showed a much higher percentage of G2M phase and proliferation index compared to the control and scramble groups (Fig. 4E). No significant differences were found between the control and scramble groups using the CCK8 assay and flow cytometry.

\section{KARGER}


Fig. 3. LF cell viability, cell cycle, and apoptosis-related mRNA expression after treating with different concentration of LPA. A: LF cell viability was estimated via a CCK-8 assay. * indicates a $24 \mathrm{~h} \mathrm{LPA}$ treatment compared with the control, \# indicates a $48 \mathrm{~h}$ LPA treatment compared with the control, $\Delta$ indicates a $72 \mathrm{~h}$ LPA treatment compared with the control, and o indicates a $96 \mathrm{~h}$ LPA treatment compared with the control. B: Comparison of LF cell mRNA expression at different concentrations of LPA. The mRNAs included are CDK1, CDK2, CDK4, CDK6, CCDN2, and CCDG2. Fold change over control = $2^{\wedge}(-\Delta \Delta \mathrm{Ct})$. C: Comparison of LF cell mRNA expression for different LPA concentrations. mRNAs studied included those for BAX, BCL2, BIM, Caspase3, Caspase7, Caspase8, and Caspase9. Fold change over control $=2^{\wedge}(-\Delta \Delta \mathrm{Ct})$. Data are presented as the mean \pm S.D. $*$ indicates $\mathrm{p}<0.05$, $* *$ indicates $\mathrm{p}<0.01, * * *$ indicates $\mathrm{p}<0.001, * * * *$ indicates $\mathrm{p}<0.0001$.

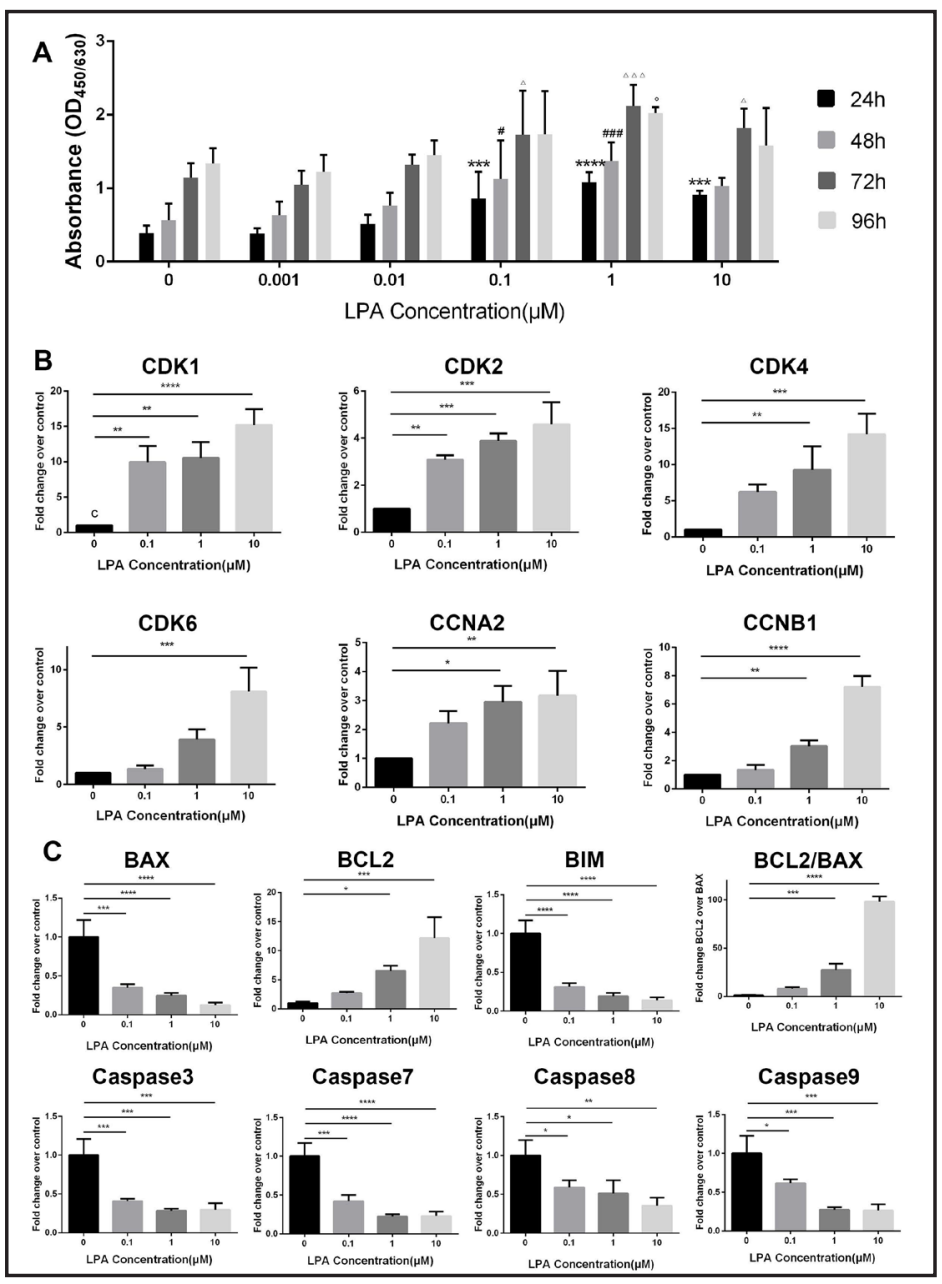

LPA inhibits apoptosis of LF cells through the Bad and Caspase family

After finding an improved cell cycle progression for LPA-treated LF cells, we analyzed apoptosis-related mRNA expression in LF cells treated with different concentrations of LPA. qPCR results revealed that the mechanism underlying anti-apoptosis in LPA-treated LF cells involves the inhibition of the BAX, BIM, and Caspase families and the activation of BCL2 (Fig. 3C). Flow cytometry showed that TNF- $\alpha$ can induce apoptosis in LF cells, and LPA can inhibit apoptosis (see online suppl. material, Suppl. Fig.1). The apoptosis rate of LF cells depleted of LPAR1 was higher than that of the scramble group, and the overexpression of LPAR1 in LF cell resulted in a much lower apoptosis rate compared to the scramble group (Fig. 4F).

LPA-LPAR1-activated Akt phosphorylation and downstream signaling cascades in LF cells

The Akt signaling pathway was reported to be downstream of LPAR1. Furthermore, members of the Cdk and Cyclin family are downstream of Akt, and Akt is known to play an important role in a cell cycle checkpoint. Proteins in the caspase family that can promote cell apoptosis are also downstream of the Akt pathway. Using western blotting, we showed that P-Akt (Ser473) was activated in a dose-dependent manner in LPA-treated LF cells (Fig. 5A). Expression of p-Akt (Ser473) cleaved Caspase 3, CDK1 (cdc2) and Cyclin-B1 (CCNB1) in LF cells with and without LPAR1 knockdown. Overexpression was analyzed using additional western blotting experiments.

When LPAR1 expression was depleted in LF cells, the activation of Akt, Cdk1, and Cyclin-B1 expression was reduced, while the activation of Caspase 3 was higher compared to the scramble control. When LPAR1 was overexpressed in LF cells, the expression of Akt, Cdk1, 
Fig. 4. LPA-induced proliferation of LF cells after LPAR1 knockdown and overexpression. A: Determination of LPAR1 expression in LF cells with or without LPAR1 knockdown or overexpression via western blotting. B: Quantification of LPAR1 expression in LF cells with or without LPAR1 knockdown or overexpression. C: LF cells with or without LPAR1 knockdown or overexpression were treated with or without LPA, and the cell viability was compared via a CCK-8 assay. D: LF cells with or without LPAR1 knockdown or overexpression were treated with

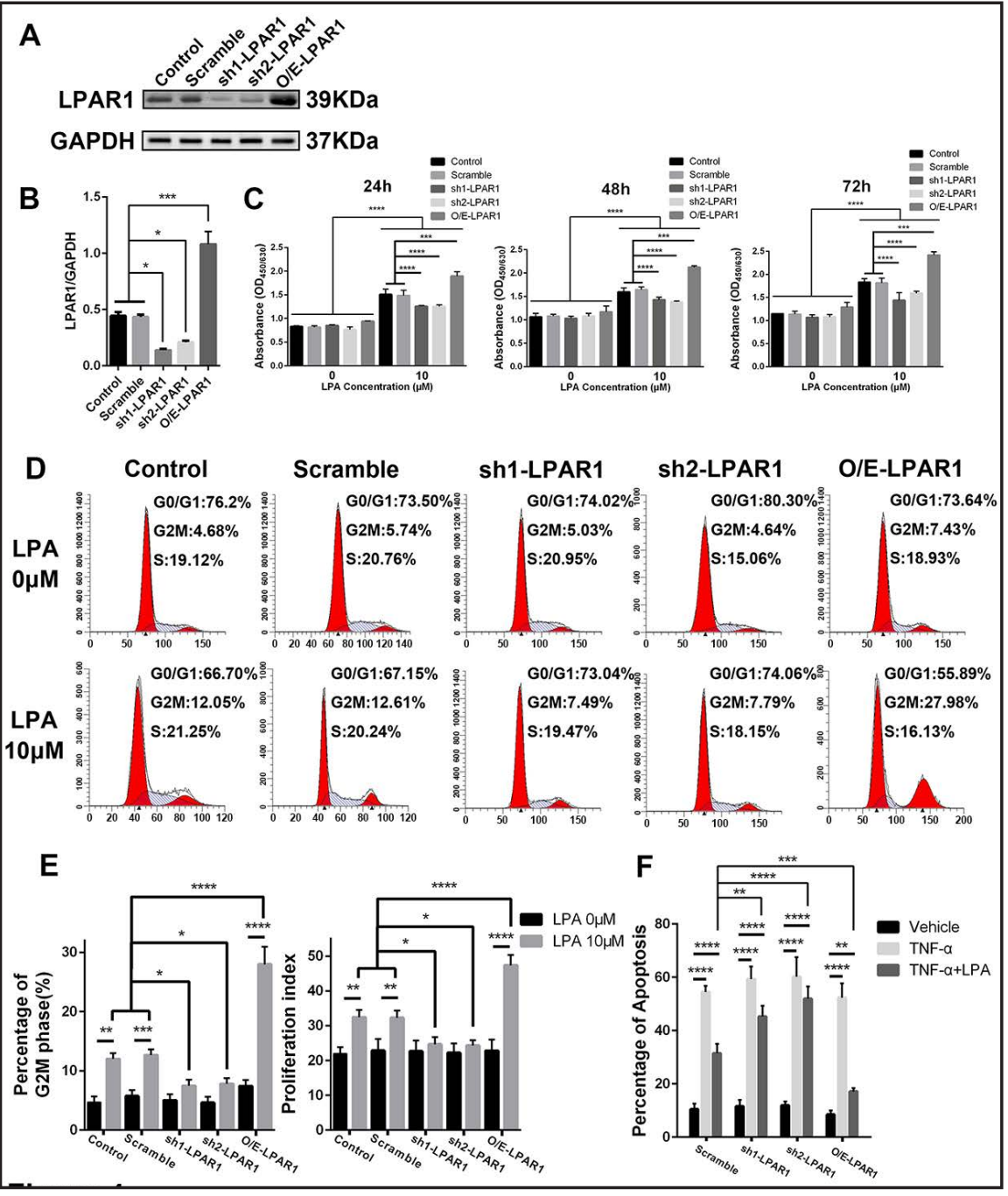
or without LPA

and the percentages of cells in the G0/G1, G2/M, or S cell cycle stages were determined via flow cytometry. $\mathrm{X}$ axis represents DNA Content $(\times 1000)$. Y axis represents Cell Number. E: Quantification of flow cytometry data using percentage of G2M phase and the proliferation index. Data are presented as the mean \pm S.D. * indicates $\mathrm{p}<0.05,{ }^{* *}$ indicates $\mathrm{p}<0.001,{ }^{* * *}$ indicates $\mathrm{p}<0.001,{ }^{* * * *}$ indicates $\mathrm{p}<0.0001$. F: Quantification of the apoptosis rate in LF cells with or without LPAR1-knockdown or LPAR1-overexpression, which were treated with or without TNF- $\alpha$ and/or LPA. Apoptosis was analyzed using flow cytometry.

and Cyclin-B1 was increased. In contrast, the activation of Caspase 3 was reduced compared to the scramble group (Fig. 5B). We confirmed the same results for Caspase 3 activation (see online suppl. material, Suppl. Fig.2D, E). Furthermore, LPA-LPAR1-induced activation of Akt can be repressed with an LPAR1 inhibitor (Ki16425), a PI3K inhibitor (LY294002), or a mTORC inhibitor (Rapamycin, PP242) (Fig. 5C).

These data suggest that Akt, Caspase 3, Cdk1, and Cyclin-B1 are potential downstream targets of LPAR1 in LPA-induced cell proliferation and survival in LF cells. Activation of Akt was induced by the LPA-LPAR1-Akt axis, and phosphorylation of Akt on Ser473 required mTORC2.

Enhanced cell proliferation and suppressed apoptosis in human hypertrophic LF samples

To further validate these findings in human pathological samples, LF tissue sections were evaluated using immunohistochemistry and immunofluorescence for BAX, cleaved 
Fig. 5. Expression of LPAR1, Akt, Caspase 3, Cdk1 and Cyclin-B1 in LPAinduced proliferation and anti-apoptosis of LF cells with and without LPAR1 knockdown and overexpres sion via western blotting. A, D: Expression of phosphorAkt (Ser473), phosphor-Akt (Thr308) in LF cells without LPAR1 knockdown and overexpression in response to LPA treatment. The results are expressed as the ratio of LPAR1 to GAPDH, pAkt (Ser473) to Akt1 and pAkt (Ser308) to Akt1. B, E: Expression of

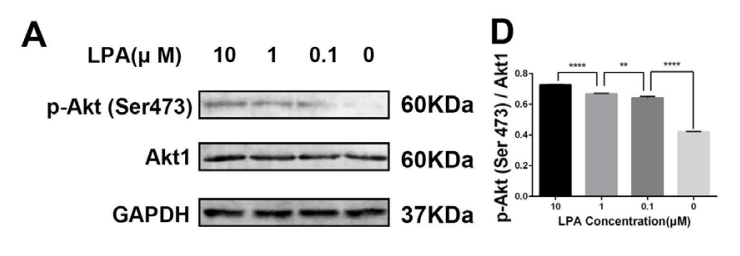

B
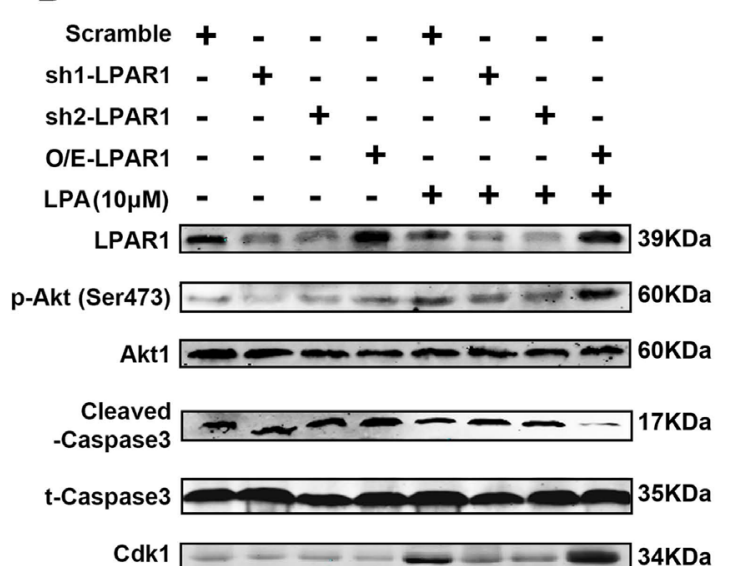

Cyclin-B1 $\square 55 \mathrm{KDa}$

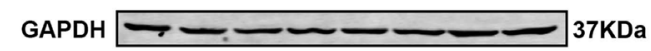

C

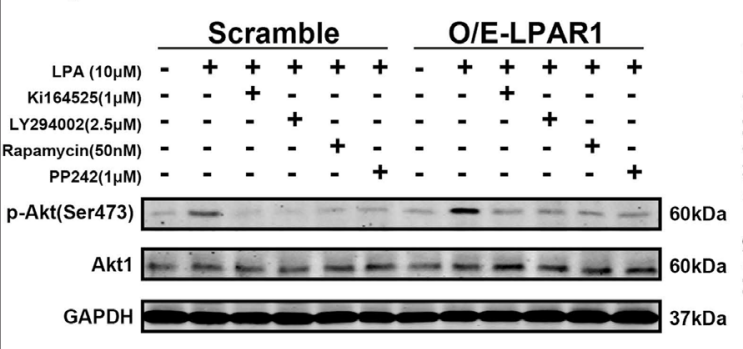

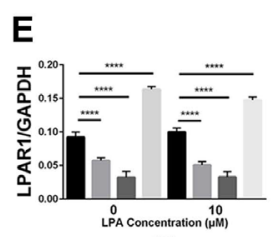
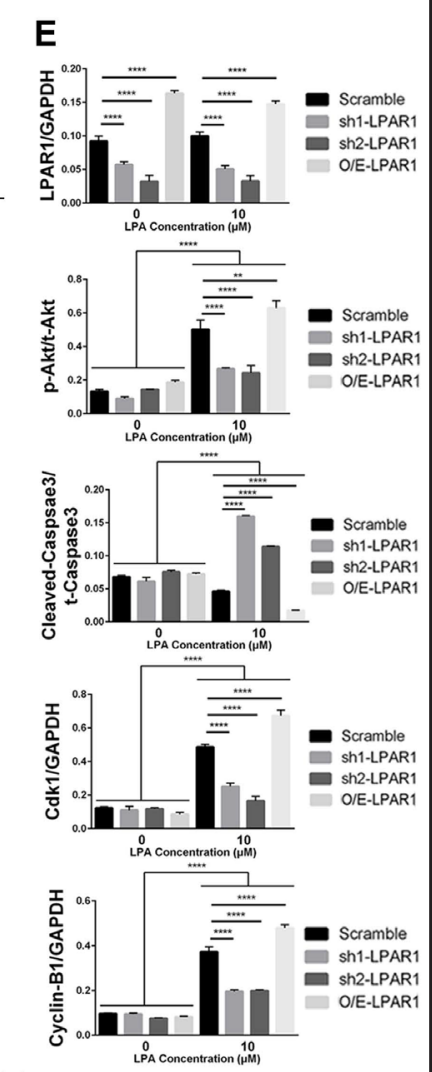

$\mathbf{F}$

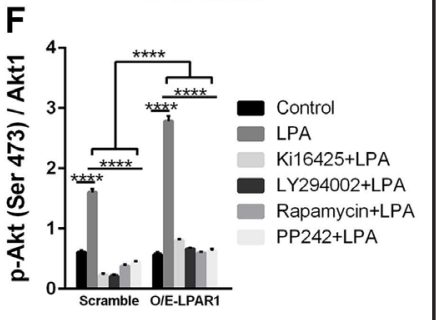
LPAR1, phosphor-Akt (Ser473), phosphor-Akt (Thr308), cleaved Caspase 3, Cdk1, and Cyclin-B1 in LF cells depleted of LPAR1 and overexpressing LPAR1 in response to LPA treatment. The results are expressed as the ratio of LPAR1 to GAPDH, p-Akt (Ser473) to Akt1, p-Akt (Ser308) to Akt1, cleaved Caspase 3 to total Caspase 3, Cdk1 to GAPDH and Cyclin-B1. C, F: Expression of phosphor-Akt (Ser473) in LF cells with or without LPAR1 overexpression treated by LPA, Ki16425, LY294002, rapamycin, and PP242. The results are expressed as the ratio of p-Akt (Ser473) to Akt1. Data are presented as the mean \pm S.D. ${ }^{* *}$ indicates $\mathrm{p}<0.01,{ }^{* * * *}$ indicates $\mathrm{p}<0.0001$.

Caspase 3, PCNA, or TUNEL. The results showed that the expression of BAX, cleaved Caspase 3 , and TUNEL staining in non-hypertrophic LF groups were significantly higher than hypertrophic LF groups. In contrast, the expression of PCNA in hypertrophic LF groups was significantly higher compared to non-hypertrophic LF groups (Fig. 6). These data suggest that LF thickness is positively correlated with cell proliferation and negatively correlated with cell apoptosis.

\section{Ki16425 prevents LPA induced LF hypertrophy in vivo}

Our in vitro data suggested that the LPA-LPAR1 signaling pathway is important for LF hypertrophy. We proposed that LPAR1 may serve as a therapeutic target for the prevention of LF hypertrophy. The inhibitory efficiency of a LPAR1 inhibitor (Ki16425) in LF cells

\section{KARGER}


Fig. 6. Immunohistochemistry and TUNEL assay of LF tissue sections from non-hypertrophic LF and hypertrophic LF. A: The expression profiles of BAX, Cleaved-Caspase 3, and PCNA were evaluated via immunohistochemistry assay. B: TUNEL assay of non-hypertrophic and hypertrophic LF tissue sections. C: Quantification of positive staining was performed using Image-Pro Plus 6.0. The results are expressed in terms of mean Integral optical density (IOD) of positive staining to cell number. Data are presented as the mean \pm S.D. ${ }^{* * * *}$ indicates $\mathrm{p}<0.0001$.

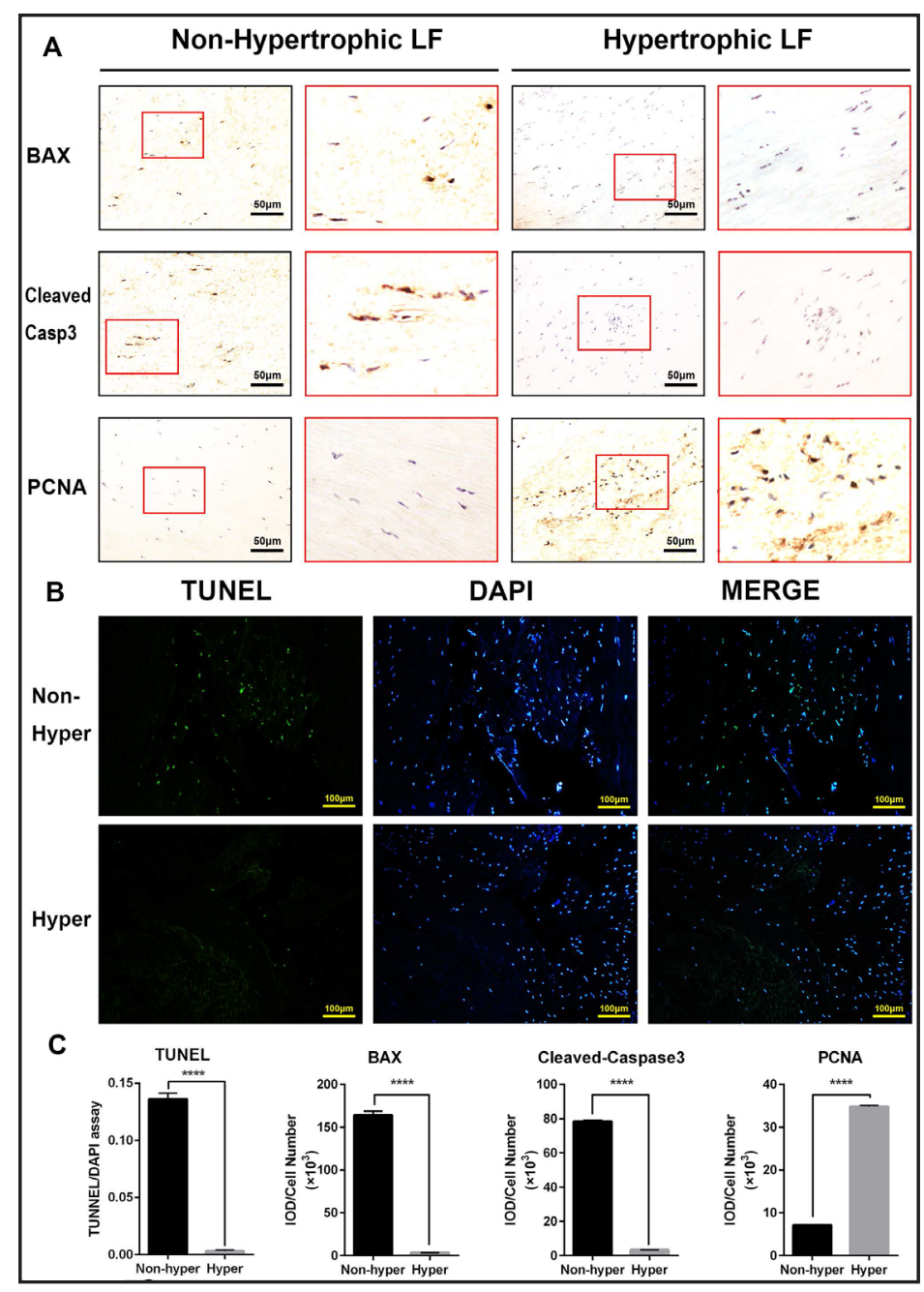

was analyzed using the CCK8 assay and western blotting. LF cell viability and activation of p-Akt (Ser473) induced by LPA was suppressed using Ki16425 (Fig. 7A, B). Following these findings, the in vivo effect of Ki16425 was analyzed in a rat LF hypertrophy model. Rat LF sections were evaluated using immunohistochemistry for LPAR1, p-Akt, cleaved Caspase 3, and PCNA. The results showed that LF was significantly thicker in LPA-treated LF groups compared to the sham groups. In contrast, the LPA+Ki16425 groups showed approximately the same thickness as the sham groups. LPA treatment of LF led to the upregulation of LPAR1, p-Akt and PCNA and the downregulation of cleaved Caspase 3 compared to the sham groups. In contrast, LF treatment with LPAR1 inhibitor treatment (Ki16425) resulted in significantly lower expression of LPAR1, p-Akt, and PCNA and higher expression of cleaved Caspase 3 compared to the sham groups. These data suggest that LF thickness is positively correlated with LPAR1 expression and regulated by the LPA-LPAR1-Akt axis (Fig. 7C, D).

\section{Discussion}

The pathological mechanism underlying LF hypertrophy is still controversial. Studies have found that the initial stage of hypertrophic LF is associated with different cytokines, including TGF- $\beta$ and VEGF secreted by degenerated and herniated intervertebral disks and facet arthrosis [11]. With the progression of intervertebral space instability and chronic inflammation, a high degree of macrophage infiltration was identified as a major cellular 
Fig. 7. Inhibitory efficiency of LPAR1 inhibitor (Ki16425) in vitro and immunohistochemistry assay of LF tissue from a rat model. A: The cell viability of LF cells treated with or without LPA and Ki16425 were compared via a CCK8 assay. B: The expression of p-Akt (Ser473) in LF cells treated with or without LPA and Ki16425 was compared via a western blot assay. The results were expressed as the ratio of p-Akt (Ser473) to Akt1. C: The expression profiles of LPAR1, p-Akt, cleaved Caspase 3, and PCNA in LPA-induced LF hypertrophy groups, Ki16425 rescue groups, and sham groups. The black broken lines indicate the outline of the LF. D: Quantification of LF thickness and positive staining were performed using Image-Pro Plus 6.0. The results are expressed in terms of mean IOD of positive staining to cell number. Data are presented as the mean \pm S.D. * indicates $\mathrm{p}<0.05$, ** indicates $\mathrm{p}<0.001, * * *$ indicates $\mathrm{p}<0.001, * * * *$ indicates $\mathrm{p}<0.0001$.

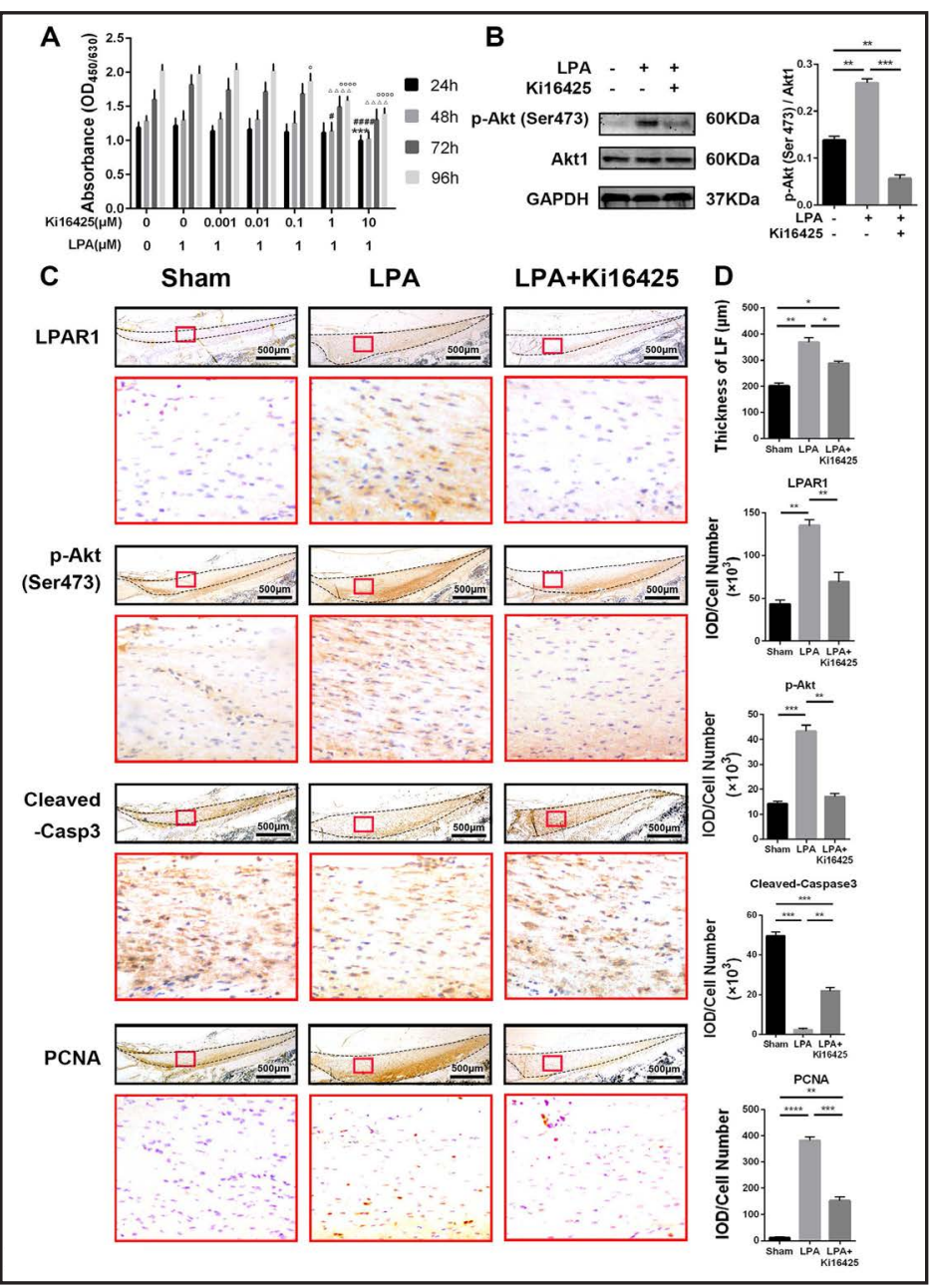

source of various molecules [12], including matrix metalloproteases (MMPs) [13, 14], tissue inhibitors of matrix metalloproteases (TIMPs) $[15,16]$ during LF hypertrophy. The LF ECM can become disorganized and show decreased levels and degeneration of elastic fibers and increased levels of collagen fibers [17]. We noted the increased levels of collagen in our study (Fig. 1B). Afterwards, VEGF mediates angiogenesis, vascular remodeling, scarring, and LF tissue repair [18].

In addition to these known cytokines, we found that LPA also contributes to the pathological development of LF hypertrophy. LPA is secreted by activated platelets in circulation, and it shows a widespread tissue distribution [19]. LPA effects cell proliferation, migration, survival, differentiation, motility, cytoskeletal change, inflammation, and cellcell interaction [6]. Many studies have demonstrated that LPA plays an important role in accelerated wound healing [20] and profibrotic action [21]. The pro-healing activity of LPA is attributed to a combined effect on fibroblast proliferation and migration and to chemotactic activity toward macrophages; these are key events in wound healing [19]. LPA-LPAR1 signaling directly drives connective tissue growth factor (CTGF) expression after injury and induces the proliferation of primary proximal tubular epithelial cells [22] and primary mesothelial cells [23]. In our study, we showed that the concentration of LPA in CSF was positively correlated with LF thickness. Like earlier studies, we showed that LPA can directly induce proliferation and anti-apoptosis of primary LF cells in vivo and in vitro. These primary LF cells can be part of the wound-healing process.

In contrast to the ubiquity of LPA in circulation, LPAR distribution is higher in the central nervous system (CNS). In particular, LPAR1 is abundant in the spinal cord [8]. Furthermore, 
increased expression of LPAR1 occurs in the pathology of degenerative conditions, like increased osteogenesis and development of arthritis [24, 25]. We showed that LPAR1 expression was correlated with hypertrophic LF (Fig. 2). The biological functions of LPA are mediated by at least six recognized cell-surface receptors (LPAR1-6) [26]. All LPA receptors signal through at least two of the four $\mathrm{G}$ subunit families and are activated after binding to $G$ protein coupled receptors (LPAR1-6) via multiple signaling pathways [5]. The most notable function of LPAR1induced Gi/o is mitogenic signaling through the RAF-MEK-MAPK cascade and survival signaling through the PI3K-Akt pathway [27, 28]. In this study, we also demonstrated that higher expression of LPAR1 occurs in hypertrophic LF compared to non-hypertrophic LF. The higher expression of LPAR1 directly mediated the effect of LPA on LF cells. This was shown by the abolished effect of LPA on LPAR1 knockdown cells and the enhanced effect of LPA on LPAR1 overexpression cells. The binding of LPA-LPAR1 subsequently activated the Akt signaling pathway, which is critical for cell proliferation and apoptosis.

Constitutive activation of the Akt pathway has been found in a variety of fibrotic diseases, including cardiac $[29,30]$, renal $[31,32]$ and pulmonary fibrosis [33, 34]. Here, we demonstrated that LPALPAR1 induced Gai/o-G $\gamma-\mathrm{G} \beta$ and PI3K in LF cells and activated Akt phosphorylation at Ser473 via TORC2

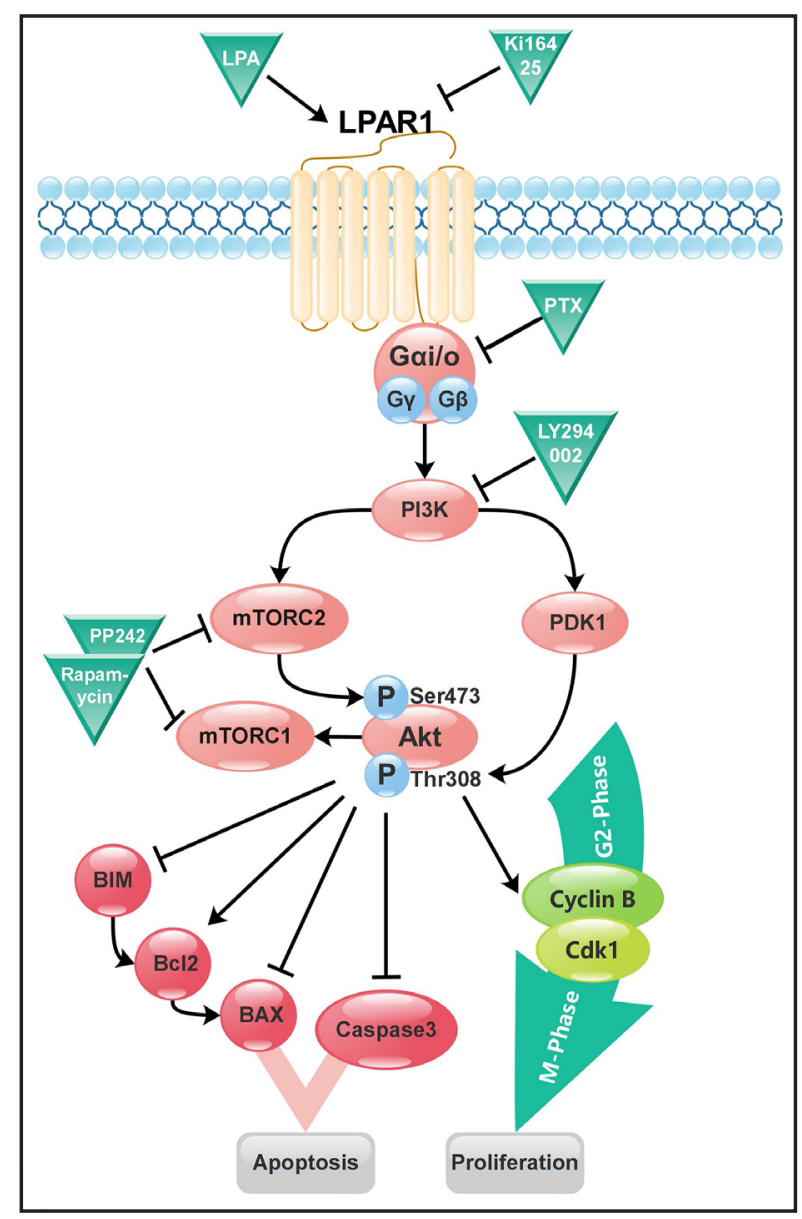

Fig. 8. A schematic diagram of the proposed mechanisms of LF cell proliferation and survival by treatment with LPA. Combining the results from our study with confirmed results from other studies, LPA activates LPAR1 (GPCR, G protein coupled receptor) and PI3K and subsequently phosphorylates Akt at Thr308 by PDK1 and Ser473 by TORC2. Afterwards, phosphorylated Akt upregulates the expression of CDK1 and Cyclin-B and triggers cell cycle progression from G2 to M phase; additionally, it inhibits BIM, BAX and cleaved Caspase 3 and facilitates Bcl2, which contributes to overall survival potentiation.

(Fig. 5C). However, it was also reported that the generation of binding sites for AKT by PI3K at the plasma membrane enables subsequent activation via phosphorylation of AKT at Thr308 by PDK1. Afterwards, p-Akt (Thr308, Ser473) directly or indirectly inhibits the Caspase and Bad families, leading to cell survival (Fig. 8). Meanwhile, p-Akt (Ser473) also activated Cdk1/Cyclin-B1 and started the M phase, which resulted in cell proliferation (Fig. 8). The hypo-expression of cleaved Caspase 3 and BAX, the hyper-expression of PCNA in hypertrophic LF from human samples (Fig. 6) and an LPA-induced hypertrophic LF animal model also suggested that LPA induces LF cell survival and proliferation, leading to LF hypertrophy (Fig. 7). As a possible mechanism to explain LF hypertrophy, LPA was reported to induce upregulation of CTGF [10, 35, 36], a process that is thought to be directly linked to fibroproliferative disorders.

Based on these data, we proposed that LPAR1 inhibition or knockdown is a potential way to rescue LPA-induced fibrosis [19]. Several LPAR1 antagonists have been used for in 


\section{Cellular Physiology Cell Physiol Biochem 2018;45:1472-1486 \begin{tabular}{l|l|l|l} 
DOI: 10.1159/000487574 & $\begin{array}{l}\text { O } 2018 \text { The Author(s). Published by S. Karger AG, Basel } \\
\text { www.karger.com/cpb }\end{array}$
\end{tabular}

vivo fibrosis treatments (Ki16425 [37], VPC-32183 [38], and AM966 [39]). LPAR1 deficiency attenuates pulmonary injury by reducing pulmonary inflammation and fibrosis [40]. LPAR1 knockdown was reported to inhibit human mesenchymal stem cell migration to reduce fibrosis [41]. Here, we showed that LPAR1 knockdown reduced the LPA-LPAR1 axis and suppressed LF cell proliferation and survival in vitro (Fig. 4). Additionally, we showed that the LPAR1 antagonist Ki16425 can reduce LPA-LPAR1-Akt axis-induced LF hypertrophy in vivo (Fig. 7).

\section{Conclusion}

In summary, our findings show that LPA-LPAR1-Akt activation is positively correlated with LF cell proliferation and survival. Our study provides deeper insight into the pathophysiological mechanism of LF hypertrophy. It also suggests that LPAR1 could become a potential target for new drugs and the development of new therapeutic methods for treatment of LF hypertrophy.

\section{Acknowledgements}

This work was supported by the National Natural Science Foundation ofChina (81501905, 81572168) and the Shanghai Hospital Development Center Foundation (SHDC2016110).

\section{Disclosure Statement}

The authors declare no conflicts of interest.

\section{References}

1 Lurie J, Tomkins-Lane C: Management of lumbar spinal stenosis. BMJ 2016;352:h6234.

-2 Kreiner DS, Shaffer WO, Baisden JL, Gilbert TJ, Summers JT, Toton JF, Hwang SW, Mendel RC, Reitman CA, North American Spine S: An evidence-based clinical guideline for the diagnosis and treatment of degenerative lumbar spinal stenosis (update). Spine J 2013;13:734-743.

-3 Yabe Y, Hagiwara Y, Ando A, Tsuchiya M, Minowa T, Takemura T, Honda M, Hatori K, Sonofuchi K, Kanazawa $\mathrm{K}$, Koide M, Sekiguchi T, Itoi E: Chondrogenic and fibrotic process in the ligamentum flavum of patients with lumbar spinal canal stenosis. Spine (Phila Pa 1976) 2015;40:429-435.

4 Sairyo K, Biyani A, Goel VK, Leaman DW, Booth R, Jr., Thomas J, Ebraheim NA, Cowgill IA, Mohan SE: Lumbar ligamentum flavum hypertrophy is due to accumulation of inflammation-related scar tissue. Spine (Phila Pa 1976) 2007;32:E340-347.

-5 Riaz A, Huang Y, Johansson S: G-Protein-Coupled Lysophosphatidic Acid Receptors and Their Regulation of AKT Signaling. Int J Mol Sci 2016;17:215.

-6 Choi JW, Herr DR, Noguchi K, Yung YC, Lee CW, Mutoh T, Lin ME, Teo ST, Park KE, Mosley AN, Chun J: LPA receptors: subtypes and biological actions. Annu Rev Pharmacol Toxicol 2010;50:157-186.

7 Yung YC, Stoddard NC, Mirendil H, Chun J: Lysophosphatidic Acid signaling in the nervous system. Neuron 2015;85:669-682.

-8 Willier S, Butt E, Grunewald TG: Lysophosphatidic acid (LPA) signalling in cell migration and cancer invasion: a focussed review and analysis of LPA receptor gene expression on the basis of more than 1700 cancer microarrays. Biol Cell 2013;105:317-333.

-9 Zhao J, Wei J, Bowser RK, Dong S, Xiao S, Zhao Y: Molecular regulation of lysophosphatidic acid receptor 1 trafficking to the cell surface. Cell Signal 2014;26:2406-2411.

10 Zhang K, Sun W, Liu XY, Zhao CQ, Li H, Sun XJ, You-Zhuan X, Ding W, Zhao J: Hypertrophy and Fibrosis of the Ligamentum Flavum in Lumbar Spinal Stenosis is Associated with Increased Expression of LPA and LPAR1 Clin Spine Surg 2016;10.1097/BSD.0000000000000048. 


\section{Cellular Physiology Cell Physiol Biochem 2018;45:1472-1486 \begin{tabular}{ll|l} 
and Biochemistry 10.1159/000487574 & $\begin{array}{l}\text { C) 2018 The Author(s). Published by S. Karger AG, Basel } \\
\text { www.karger.com/cpb }\end{array}$ \\
Published onlIne: February 21, 2018
\end{tabular}

11 Ren L, Hu H, Sun X, Li F, Zhou JJ, Wang YM: The roles of inflammatory cytokines in the pathogenesis of ossification of ligamentum flavum. Am J Transl Res 2013;5:582-585.

12 Chen J, Liu Z, Zhong G, Qian L, Li Z, Qiao Z, Chen B, Wang H: Hypertrophy of ligamentum flavum in lumbar spine stenosis is associated with increased miR-155 level. Dis Markers 2014;2014:786543.

13 Cui G, Watanabe K, Miyauchi Y, Hosogane N, Tsuji T, Ishii K, Nakamura M, Toyama Y, Chiba K, Miyamoto T, Matsumoto M: Matrix metalloproteinase 13 in the ligamentum flavum from lumbar spinal canal stenosis patients with and without diabetes mellitus. J Orthop Sci 2011;16:785-790.

14 Oh IS, Ha KY: Matrix metalloproteinase-3 on ligamentum flavum in degenerative lumbar spondylolisthesis. Spine (Phila Pa 1976) 2009;34:E552-557.

$\rightarrow 15$ Xu YQ, Zhang ZH, Zheng YF, Feng SQ: MicroRNA-221 Regulates Hypertrophy of Ligamentum Flavum in Lumbar Spinal Stenosis by Targeting TIMP-2. Spine (Phila Pa 1976) 2016;41:275-282.

16 Park JB, Lee JK, Park SJ, Riew KD: Hypertrophy of ligamentum flavum in lumbar spinal stenosis associated with increased proteinase inhibitor concentration. J Bone Joint Surg Am 2005;87:2750-2757.

-17 Kosaka H, Sairyo K, Biyani A, Leaman D, Yeasting R, Higashino K, Sakai T, Katoh S, Sano T, Goel VK, Yasui $\mathrm{N}$ : Pathomechanism of loss of elasticity and hypertrophy of lumbar ligamentum flavum in elderly patients with lumbar spinal canal stenosis. Spine (Phila Pa 1976) 2007;32:2805-2811.

18 Hur JW, Kim BJ, Park JH, Kim JH, Park YK, Kwon TH, Moon HJ: The Mechanism of Ligamentum Flavum Hypertrophy: Introducing Angiogenesis as a Critical Link That Couples Mechanical Stress and Hypertrophy. Neurosurgery 2015;77:274-281; discussion 281-272.

19 Rancoule C, Pradere JP, Gonzalez J, Klein J, Valet P, Bascands JL, Schanstra JP, Saulnier-Blache JS: Lysophosphatidic acid-1-receptor targeting agents for fibrosis. Expert Opin Investig Drugs 2011;20:657667.

20 Sturm A, Sudermann T, Schulte KM, Goebell H, Dignass AU: Modulation of intestinal epithelial wound healing in vitro and in vivo by lysophosphatidic acid. Gastroenterology 1999;117:368-377.

-21 Jeon ES, Lee IH, Heo SC, Shin SH, Choi YJ, Park JH, Park DY, Kim JH: Mesenchymal stem cells stimulate angiogenesis in a murine xenograft model of A549 human adenocarcinoma through an LPA1 receptordependent mechanism. Biochim Biophys Acta 2010;1801:1205-1213.

-22 Sakai N, Chun J, Duffield JS, Lagares D, Wada T, Luster AD, Tager AM: Lysophosphatidic acid signaling through its receptor initiates profibrotic epithelial cell fibroblast communication mediated by epithelial cell derived connective tissue growth factor. Kidney Int 2017;91:628-641.

23 Sakai N, Chun J, Duffield JS, Wada T, Luster AD, Tager AM: LPA1-induced cytoskeleton reorganization drives fibrosis through CTGF-dependent fibroblast proliferation. FASEB J 2013;27:1830-1846.

24 Liu YB, Kharode Y, Bodine PV, Yaworsky PJ, Robinson JA, Billiard J: LPA induces osteoblast differentiation through interplay of two receptors: LPA1 and LPA4 J Cell Biochem 2010;109:794-800.

25 Gennero I, Laurencin-Dalicieux S, Conte-Auriol F, Briand-Mesange F, Laurencin D, Rue J, Beton N, Malet N, Mus M, Tokumura A, Bourin P, Vico L, Brunel G, Oreffo RO, Chun J, Salles JP: Absence of the lysophosphatidic acid receptor LPA1 results in abnormal bone development and decreased bone mass. Bone 2011;49:395403.

26 Yung YC, Stoddard NC, Chun J: LPA receptor signaling: pharmacology, physiology, and pathophysiology. J Lipid Res 2014;55:1192-1214.

27 Fang X, Yu S, LaPushin R, Lu Y, Furui T, Penn LZ, Stokoe D, Erickson JR, Bast RC, Jr., Mills GB: Lysophosphatidic acid prevents apoptosis in fibroblasts via G(i)-protein-mediated activation of mitogenactivated protein kinase. Biochem J 2000;352 Pt 1:135-143.

28 Ye X, Ishii I, Kingsbury MA, Chun J: Lysophosphatidic acid as a novel cell survival/apoptotic factor. Biochim Biophys Acta 2002;1585:108-113.

29 Zhao QD, Viswanadhapalli S, Williams P, Shi Q Tan C, Yi X, Bhandari B, Abboud HE: NADPH oxidase 4 induces cardiac fibrosis and hypertrophy through activating Akt/mTOR and NFkappaB signaling pathways. Circulation 2015;131:643-655.

30 Shimizu I, Minamino T: Physiological and pathological cardiac hypertrophy. J Mol Cell Cardiol 2016;97:245262.

31 Liu M, Ning X, Li R, Yang Z, Yang X, Sun S, Qian Q: Signalling pathways involved in hypoxia-induced renal fibrosis. J Cell Mol Med 2017;10.1111/jcmm.13060 


\section{Cellular Physiology Cell Physiol Biochem 2018;45:1472-1486

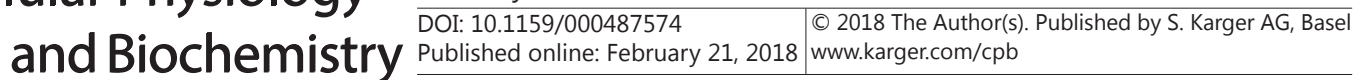

-32 Rampanelli E, Rouschop KM, Claessen N, Teske GJ, Pals ST, Leemans JC, Florquin S: Opposite role of CD44-standard and CD44-variant-3 in tubular injury and development of renal fibrosis during chronic obstructive nephropathy. Kidney Int 2014;86:558-569.

-33 Zhang PX, Cheng J, Zou S, D’Souza AD, Koff JL, Lu J, Lee PJ, Krause DS, Egan ME, Bruscia EM: Pharmacological modulation of the AKT/microRNA-199a-5p/CAV1 pathway ameliorates cystic fibrosis lung hyper-inflammation. Nat Commun 2015;6:6221.

-34 Yan Z, Kui Z, Ping Z: Reviews and prospectives of signaling pathway analysis in idiopathic pulmonary fibrosis. Autoimmun Rev 2014;13:1020-1025.

-35 Heusinger-Ribeiro J, Eberlein M, Wahab NA, Goppelt-Struebe M: Expression of connective tissue growth factor in human renal fibroblasts: regulatory roles of RhoA and cAMP. J Am Soc Nephrol 2001;12:18531861.

-36 Zhong ZM, Zha DS, Xiao WD, Wu SH, Wu Q, Zhang Y, Liu FQ Chen JT: Hypertrophy of ligamentum flavum in lumbar spine stenosis associated with the increased expression of connective tissue growth factor. J Orthop Res 2011;29:1592-1597.

-37 Zhao J, Wei J, Weathington N, Jacko AM, Huang H, Tsung A, Zhao Y: Lysophosphatidic acid receptor 1 antagonist ki16425 blunts abdominal and systemic inflammation in a mouse model of peritoneal sepsis. Transl Res 2015;166:80-88.

-38 Jeon ES, Kim JH, Ryu H, Kim EK: Lysophosphatidic acid activates TGFBIp expression in human corneal fibroblasts through a TGF-beta1-dependent pathway. Cell Signal 2012;24:1241-1250.

-39 Olianas MC, Dedoni S, Onali P: Antidepressants activate the lysophosphatidic acid receptor LPA(1) to induce insulin-like growth factor-I receptor transactivation, stimulation of ERK1/2 signaling and cell proliferation in CHO-K1 fibroblasts. Biochem Pharmacol 2015;95:311-323.

40 Chen X, Walther FJ, van Boxtel R, Laghmani EH, Sengers RM, Folkerts G, DeRuiter MC, Cuppen E, Wagenaar GT: Deficiency or inhibition of lysophosphatidic acid receptor 1 protects against hyperoxia-induced lung injury in neonatal rats. Acta Physiol (Oxf) 2016;216:358-375.

41 Ryu JM, Han HJ: Autotaxin-LPA axis regulates hMSC migration by adherent junction disruption and cytoskeletal rearrangement via LPAR1/3-dependent PKC/GSK3beta/beta-catenin and PKC/Rho GTPase pathways. Stem Cells 2015;33:819-832. 